\title{
TRANSINDIVIDUALITY AND POST-LABOR BASED ON SIMONDON AND STIEGLER*
}

\author{
Jae-Hee Kim** \\ https://orcid.org/0000-0001-9871-2636 \\ kimjh@eulji.ac.kr
}

\begin{abstract}
This article aims to elucidate a philosophical foundation of a post-labor paradigm through the transindividual technical-psychic-collective culture based on Gilbert Simondon and Bernard Stiegler. Simondon predicts that the problem of the alienation of labor due to mechanical industrialization can be overcome through the spread of post-industrial technical culture based on both technical mentality and information technology (IT). In contrast, Stiegler claims that, along with information networks, hyper-industrialization rather than post-industrialization has arrived and that, in order to recover human values in a machine empire devoid of caring, the strengthening of the ability for non-automation based on automaticity is necessary. However, Simondon's technical culture beyond labor implies a posthumanistic vision in that it assumes the capacity of technology to mediate between the preindividual and the transindividual beyond technical instrumentalism, which is anthropocentric, and opens up transductive relationships among humans and non-humans. I will argue that Stiegler's urgent proposal that seeks to save human life from the control of a techno-capital system, such as the reinvention of work transcending employment, must be concretized within the Simondonian posthumanistic project.
\end{abstract}

Keywords Simondon; Stiegler; Post-labor; Transindividuality; Technology.

* Article submitted on 04/05/18 and approved on 10/07/18. This paper was supported by Eulji University in 2018.

** Eulji University - Faculty of Liberal Arts, Philosophy. Seongnam, Republic of Korea.

KRITERION, Belo Horizonte, nº 143, Ago./2019, p. 319-338 
RESUMO O objetivo deste artigo é elucidar a base filosófica do paradigma pós-laboral por meio da cultura técnica-psiquica-coletiva transindividual de Gilbert Simondon e Bernard Stiegler. Simondon prediz que o problema da alienação laboral surgido da industrialização mecânica pode ser vencido mediante a expansão da cultura técnica pós-industrial baseada tanto na mentalidade técnica quanto na tecnologia da informação (TI). Em contraste, Stiegler afirma que, além das redes de informação, a hiper-industrialização se estabeleceu para além da pós-industrialização e que, para recuperar valores humanos em um império das máquinas sem carinho, é necessário o fortalecimento da capacidade de não automação baseada em automatismo. Entretanto, a cultura técnica além do trabalho de Simondon implica uma visão pós-humanista em que se presume a capacidade da tecnologia em mediar entre o pré-individual e o transindividual, que é antropocêntrico, e inaugura relações transdutivas entre humanos e não humanos. Defendo que a proposta urgente de Stiegler busca salvar a vida humana do controle de um sistema de tecno-capital, como a reinvenção do trabalho transcendendo o emprego deve ser concretizada dentro do projeto pós-humanista simondoniano.

Palavras-chave Simondon, Stiegler, Pós-labor, Transindividualidade, Tecnologia.

\section{Introduction}

At actual sites of labor, where the evolution of humans and the evolution of machines have been developing concurrently, the fear is spreading that AI machines will replace humans by either turning the latter into simple machines or rendering them redundant. The emergence of AI machines is a signal indicating that a labor-centered society based on the human body's capacity for action has already reached a critical point. The transition from the Anthropocene epoch to the Algoricene epoch and the opening up of posthuman society not only negate the opposition between humans and machines surrounding labor, but also urge fundamental changes in the concept of labor itself. Rather than reducing alienation related to AI machines to the problem of jobs, the possibility of a post-labor era, where humans and non-human machines can work together, must be considered. This post-labor symbiosis is contingent on a fundamental rethinking of how humans view labor and work.

This paper seeks to elucidate a philosophical foundation of a post-labor paradigm based on transindividual technical-psychic-collective culture of 
genuine communication, instead of the disindividuated and uniform mass collectivity of technocratic consumer capitalism, through the insights of Gilbert Simondon and Bernard Stiegler. These figures are noteworthy in that, while affirming the technical environment as a fundamental condition of human life, they theorized new ways of forming relationships between technology and humans. In particular, they are pioneers in viewing technical automation as an opportunity for a post-labor system and presenting a possibility of transindividual collectivization that transcends labor communities. Simondon notes the ways in which technical objects exist and seeks to overcome Karl Marx's economic paradigm regarding the alienation of labor through transindividual technical culture. Stiegler, on the other hand, critically inherits Simondon's project through techno-pharmacology of the hyper-industrialized technical environment subsequent to Simondon. Based on Stiegler and Simondon's work, in order for posthuman society based on digital IT to be able to realize a new humanism of human-nonhuman networks instead of a dystopia of a mechanical empire, it is necessary to fulfill one of two conditions. The first option is to enable conditions for the free performance of technical activities of invention and creation instead of labor, and the second condition is to enable conditions of work for self-realization instead of employment for livelihood. Such a task demands not only the innovation of economic conditions but also the realization of transindividual psychic-collective culture based on the critical simultaneous use of technical knowledge and technical networks. In this study, I will review Simondon's pioneering insights into labor, technology, and alienation and their critical inheritance in Stiegler's arguments and through this process search for the possibility of transindividual technical culture as a post-labor model in an era of technical automation.

\section{Simondon's Transindividual Technical Culture beyond Labor}

In Du Mode d'existence des objets technique (1958), ${ }^{1}$ Simondon discusses the limitations of labor communities faced with the development of technology and seeks to resolve the problem of human alienation due to mechanization and automation in innovative ways. This human alienation emerged during the transition from manual workshops to mechanized factories at the end of the 19th century. Marx perceives the source of this alienation to be in the opposition between labor and capital surrounding the possession of means of production,

1 The number of pages referenced below is based on English translations. On the Mode of Existence of Technical Object (2017). 
while Simondon perceives it to be in the "physio-psychological discontinuity" between technical individuals and human individuals. ${ }^{2}$ To phrase it in a different way, before industrialization, artisans moved tools with their bodies and were able to feel both the accuracy of their gestures and the operation of the tools. After industrialization, a previously non-existent alienation emerged as technical objects became increasingly automated and machines began to move in their own ways instead of wholly depending on human movements. In Simondon's view, such patterns of alienation are difficult to explain solely based on the opposition between labor and capital. He admits that the asymmetrical structure between capital and labor distorts the relationship between humans and machines and that the non-possession of means of production widens the distance between machines and laborers. Simondon's emphasis is on the fact that regardless of whether they are laborers or capitalists, humans can no longer form adequate relationships with machines due to their lack of understanding of individuated technical objects. This sense of alienation stems also from the fact that, especially because humans played the "role of [a] tool bearer" (Simondon, 2017, p. 80) instead for a long time before the emergence of technical individuals, they have understood themselves as technical individuals to the extent of believing that they are unjustly deprived of their roles by automatic machines.

In "La mentalité technique" (1961), ${ }^{3}$ Simondon explains that this "physiopsychological discontinuity" between humans and machines, which appears in the industrial mode of production, strengthens discontinuity in relationships among humans. In the case of the artisanal mode, where technical objects remain on the level of tools, both information sources and energy sources lie in human operators. Energy is the use of muscular strength; learned and transmitted, information is the actual implementation of sensory devices that control and regulate the application of gestures; and operation is the performance according to continuous schemata on entities that belong to the same scale as human operators. The distance between the operation of labor and the conditions of use of the products of labor is relatively short, and the relationship between human beings and nature, too, is direct. In other words, in the artisanal mode, the interactive trilateral relationship among nature, humans, and technical objects is physio-psychologically continuous. In contrast, in the case of the industrial mode, where technical objects reach the level of machines, this trilateral

2 "The alienation of man in relation to the machine does not only have a socio-economic sense; it also has a physio-psychological sense; the machine no longer prolongs the corporal schema, neither for workers, nor for those who possess the machines" (Simondon, 2017, p. 133).

3 The number of pages referenced below is based on English translations. "Technical Mentality" (2009). 
relationship becomes discontinuous. Humans as information sources and nature as an energy source are separated and information's effect of modulating energy is realized through machines that act as relays. In particular, as information sources are divided on diverse levels, human alienation is further accelerated. That is, as the functions of the same human being undergo professionalizationspecialization into an inventor, a constructor, or an operator according to an "anatomy of work," humans' relationships with not only nature and technical objects but also other humans become discontinuous. ${ }^{4}$

If so, then how does Simondon see such alienation, or discontinuity among nature, humans, and technical objects, as surmountable? His solution is not to reject automatic machines or to return to the pre-industrial mode but to conciliate the disparity (disparité) between the artisanal mode and the industrial mode transductively, thus recovering a continuous relationship between the two on a new level. A methodology unique to Simondon, transduction is to discover a compatible order among things that are incompatible and disparate on a higher level and to establish solutions for metastable equilibrium, just as two disparate retinal images forge a relationship at a third spot and resolve the disproportion in vision. He finds a solution to that discontinuity in technical culture, which is a more advanced perspective that takes into consideration the operational functioning of the entire system, where nature, humans, and technical objects interact and coevolve. In my view, Simondon's solution is noteworthy even today, which is faced with a similar difficulty of the opposition between humans and technology, in that it seeks to convert emotional disparity and conflicts among ways of life due to industrialization and technical individuation into an occasion for the emergence of post-labor technical culture beyond the level of economic alienation such as labor and production.

According to Simondon,

The collectivization of the means of production cannot achieve a reduction of alienation on its own; it can only achieve this reduction if it is the precondition for the acquisition of the intelligence of the individuated technical object by the human individual. This relation between the human individual and the technical individual is the most difficult to form. It presupposes a technical culture, which introduces the capacity of different attitudes rather than that of work and of action (2017, p. 134).

4 "The figure of the unhappy inventor came about at the same time as that of the dehumanized worker: it is its counter-type and it arises from the same cause. To put itself at the dimension of the machine's energy entry, the information entry complicates itself, becomes divided and specialized, with the result that the human being is not only isolated from nature but also from himself, and enclosed in piecemeal tasks, even as inventor" (Simondon, 2009, p. 21). 
The technical culture is to adopt an attitude not of human labor, which pays attention to the purposiveness of the results of actions, but of the "automatism of the machine," which pays attention to the internal coherence of the selfregulating function (Simondon, 2017, p. 135). A truly mutually cooperative relationship between humans and machines can be achieved not on the level of the economy or energy, which assumes machines to be tools of human labor, but on the operational functioning level of self-regulating systems, in which humans and machines participate together. So, "in order to reduce alienation, one would have to bring the aspect of work, of effort, of concrete application implying the use of the body, and of the interaction of function back to the unity of technical activity" (Simondon, 2017, p. 256). Simondon understands technical activities, which pay attention to operational functioning, as a category more comprehensive and fundamental than labor, which focuses on productivity. Labor is a concept appropriate only to the artisanal mode, where the relationship between technical objects and humans was continuous through physical connection, and humans, as tool bearers, assumed the role of technical individuals instead. In contrast, the "technical activity distinguishes itself from mere work, and from alienating work, in that technical activity comprises not only the use of the machine, but also a certain coefficient of attention to the technical functioning, maintenance, adjustment, and improvement of the machine, which continues the activity of invention and construction" (Simondon, 2017, p. 255). Simondon's main argument is that labor therefore must be replaced by technical activities.

In fact, his critique of the concept of labor is rooted more in terms of ontogenetic ontology and axiology than of the history of technology. According to Simondon, labor assumes an opposition between form (eidos; human intentionsmaster-domination) and matter (hyle; passive nature-slave-subjugation) and suggests viewing the relationship between humans and nature and the relationship between humans and technology within the framework of domination and subjugation. In addition, it directs focus only to the given state of the two terms of form and matter and overlooks technical operation, which is a process of interaction between these two terms. Just as the individual-centered hylomorphism schema prevents one from pondering on individuation, none other than the concept of labor prevents the pondering of technical activities. ${ }^{5}$

5 Because Simondon's theory of individuation presumes the ontogenetic process of metastable systems as more fundamental than individuals themselves, a main object of its critique is the substantialist and individual-centered hylomorphism schema. Because the hylomorphism schema was universalized as a paradigm explaining the generation and individuation of beings based on the very incomplete technical experiences of Aristotle's times, it not only has ontological and epistemological defects in itself but also has the serious problem of unfairly spreading misunderstandings of technical operation. " $[\mathrm{T}]$ he hylomorphic schema represents the transposition 
It is clear that technical culture based on these technical activities cannot be reduced to technocratism. If technocratism assumes humans' conquest of nature and the enslavement of machines for humans' freedom, this technical culture assumes the ways in which nature-humans-machines form relationships as equal and mutually cooperative beings based on the exchange and communication of information and not from the perspective of use or possession. It is a culture from which axiological prejudices and epistemological and practical severance between artisans' technology (handicraft) and engineers' technology (technological engineering) have been removed, a culture from which hierarchy and discrimination between physical labor and mental labor has disappeared, especially a culture in which not a laborer or a capitalist but a "psychologist of machines, or a sociologist of machines - what we might call a mechanologist" (Simondon, 2017, p. 160) can proudly acquire a social status and stand in the ranks of cultural creators such as writers and artists.

It is noteworthy that that this technical culture transcending labor is based on transindividual collective relationships. Transindividual relationships are not social relationships ensuing from the division of labor, but are constructed when new emotional solidarity is realized among individuated humans through technical objects that bear the potentials of preindividual nature. According to Simondon's L'Individuation à la lumière des notions de forme et d'information (2005), transindividuality does not signify relationships of solidarity or communication among individuals who are separate in already given groups, as is the case with intersubjectivity or interindividuality. It is generated when preindividual potentials inherent as the "weight of nature" in human individuals who were previously separate as members of a biological species cut across those individuals and are connected to one another on affective and emotional levels, and psychic individuation through internal self-transcendence and collective individuation through external participation are formed simultaneously (the 'syncrystallization' of the two). This simultaneously psychic and collective transindividual relationship is not based on the "biological grouping of solidarity and division of labor" (Simondon, 2005, p. 302). Simondon argues that, as something transcending the biological level of labor communities, this

into philosophical thought of the technical operation reduced to work, and taken as a universal paradigm of the genesis of being. It is indeed a technical experience, but a very incomplete technical experience that is at the basis of this paradigm. The generalized use of the hylomorphic schema in philosophy introduces an obscurity that comes from the insufficiency of this schema's technical basis" (Simondon, 2017, p. 248). 
transindividual collectiveness of the affective-emotional solidarity unique to humans is realized through the mediation of none other than technical objects. ${ }^{6}$

Above the social community of work and beyond the inter-individual relationship not supported by an operational activity, a mental and practical universe of technicity establishes itself, in which human beings communicate through what they invent. The technical object taken according to its essence, which is to say the technical object insofar as it has been invented, thought and willed, and taken up by a human subject, becomes the medium and symbol of this relationship, which we would like to name transindividual (Simondon, 2017, p. 252).

To Simondon, technology essentially belongs to a "dark zone" between capital and labor. The categories of capital and labor conceal the true nature of technical activities and alienate humans from the technical essence. Technology is not a tool of production, but rather something that mediates the preindividual and the transindividual. Likewise, invention, which characterizes technical activities, is not an activity of biological individuals, but of transindividual subjects. The subjects of invention bear the charge of unindividuated nature so that they, as beings vaster and richer than individuals, invent based on the preindividual potentials that are united with them. In addition, the technical objects invented transmit this preindividual reality to other beings, transcending time and space. It is specifically in this respect that Simondon sees technical objects not merely as humans' simple tools but as essential media realizing transindividual relationships among humans. In these transindividual relationships, humans and technical objects form a relationship of mutually cooperative coexistence in that they both are beings bearing and communicating the preindividual charge. ${ }^{7}$ In other words, to Simondon, technology is not a condition of labor and production but is a condition of transindividual post-labor culture of human-nonhuman networks that realize preindividual reality.

Simondon predicts the possible realization for such a transindividual technical culture, especially in the post-industrial mode of production based on IT networks. According to "La mentalité technique" (1961), in the post-industrial mode of production, which transductively resolves the disparity and conflicts between the artisanal mode of production and the industrial mode of production, an ensemble where nature-machines-humans form a continuous relationship can

6 Though Individuation in the Light of the Notions of Form and Information does not address technology in direct relation to transindividuality or psychic-collective individuation, "Conclusion" in On the Mode of Existence of Technical Objects mentions transindividuality a total of seven times. When considered in terms of the simultaneous submission of the two works as Simondon's doctoral dissertation (1958), "Conclusion" can be understood as a unique text bridging these works within his entire thought.

7 As for Simondon's view on technology and transindividual relationship, see Jae-Hee Kim, 2017, pp. 403-408. 
be constructed through both technical mentality and technical objects, which focus on open networks. This is because disparate functions (technicians, laborers, managers, et al.) providing information to machines are not fragmented but are connected to one another so that not only technical reality can be experienced as whole but also technical products are simultaneously inserted into the natural world and the human world, thus becoming capable of forming a part of the entire network. Technical mentality is unlike the attitude of consumers in taking into consideration non-essential characteristics of technical objects when selecting automobiles, for example. Technical mentality is an attitude unique to technical activities, whereby the world is understood and used through cognitive schemas that focus on operational functioning. As the power of analogical interpretation that transcends boundaries, technical mentality produces "transcategorical knowledge," which makes it possible to discover common modes of regime of functional operation in disparate orders of all entities including the human and the non-human (Simondon, 2009, p. 18). ${ }^{8}$ Consequently, it is capable of developing schemas and values of actions that can create mutually cooperative networks among nature-technology-humans. Simondon cites, as the basic postulates of this technical mentality, the relative detachability of subparts and considerations of the entelechy of operating systems that have structural conditions as thresholds. ${ }^{9}$ Technical activities that follow these postulates can produce, as post-industrial technical objects, metastable and open objects that can always be renewed through the replacement and rearrangement of subparts instead of absolutely indivisible and unchanging metaphysical substances. ${ }^{10}$ By

8 Simondon presents Cartesian mechanisms and cybernetic theories as representative examples of technical cognitive schemas. If Cartesian mechanisms are cases where the cognitive schema of "transfer without losses" has been expanded and applied to the mechanical motion of a pulley machine and logical deduction, then cybernetics can be seen as a case where the cognitive schema of "feedback-regulating operation that actively adjusts to purposiveness" has been expanded and applied to automatically regulated mechanical devices, living organisms' behavior, and geographical and meteorological phenomena (2009, pp. 17-18).

9 "[P]ostulates of the 'technical mentality': 1. The subsets are relatively detachable from the whole of which they are a part. [...] 2. The second postulate is that of the levels and the regimes: if one wants to understand a being completely, one must study it by considering it in its entelechy, and not in its inactivity or its static state" (Simondon, 2009, p. 19).

10 "[T]he postindustrial technical object is the unity of two layers of reality: a layer that is as stable and permanent as possible, which adheres to the user and is made to last; and a layer that can be perpetually replaced, changed, renewed, because it is made up of elements that are all similar, impersonal, mass-produced by industry and distributed by all the networks of exchange. It is through participation to this network that the technical object always remains contemporary to its use, always new" (Simondon, 2009, p. 24). Interestingly, Simondon tends to equate post-industrial technical objects with techno-aesthetic objects. He highly evaluates the Eiffel Tower and the Garabit Viaduct as having existence value as a "part of this multifunctional network that marks the key points of the geographical and human world" $(2009$, p. 22) instead of mere expressions of industrial might that have succeeded as spectacles. However, being simultaneously inserted into the key points of the two worlds of nature and humans is something that Simondon cites as a characteristic of aesthetic objects as well (2017, p. 196). In Simondon's world, technical objects are aesthetic when they are faithful to their essential function as open beings forging a relationship between nature and humans. 
reconnecting energy and information that were disconnected in the industrial mode, IT networks transductively integrate artisans' workshops and industrial factories into post-industrial laboratories. As if predicting the "maker activities" of today, subparts mass-produced in these post-industrial laboratories through industrial standardization are produced as post-industrial technical objects through the free assembly and manufacturing activities of technicians who are "both intellectual and handy" (Simondon, 2009, p. 22) and have united the separated functions of the inventor, constructor, and operator.

In conclusion, in Simondon's view, the post-industrial mode based on information networks corresponds to the basis of the technical culture of transindividual post-labor that realizes the ensemble of nature-machines-humans. In Simondon's view, transindividual groups based on the technical activities of creative invention constitute a far more evolved form of human society than do communities based on the labor of the biological human species. To him, the problem of alienation revealed by the opposition between humans and machines exists in the ways in which humans and technology formed a relationship that failed to be appropriately regulated in correspondence with the evolution of technology, and not in technology itself. The initial optimism about technology that had been regulated within human control changed into fear of technology that developed beyond human control. When this occurred, most attention focused on exitless critique of technology and concerns about jobs within the framework of labor and production. In contrast, Simondon shows a possibility of resolving this issue by reinventing humans' relationship to technology. According to him, in the IT age of the 21 st century it must be possible for humans to exist not as laborers, who are powerlessly spent before machines and destroy the latter because they have lost their means of labor, but to emerge as active technicians, who understand the operation of machines, organize the relationships among machines, and can construct technical ensembles. The fact that the human-machine relationship is still tied to the labor paradigm even though technology has developed to the level of ensembles of information networks beyond the level of individuals of the thermodynamic era, above all, perpetuates humans' alienation from technology. This does not mean that the development of technology and the so-called 4th Industrial Revolution will automatically realize post-labor transindividual culture. Simondon likewise emphasizes:

Such a [technical] mentality can only develop if the affective antinomy of the opposition between the artisanal modality and the industrial one is replaced by the firm orientation of a voluntary push towards the development of technical networks, which are postindustrial and thus recover a continuous level [of operation] (2009, p. 24). 
In my view, both the spread of such a technical mentality, which seeks to be liberated from the frameworks of labor and production and to ponder on the relationships among nature-machines-humans totally within essential networks, and the establishment of technical culture based on transindividual relationships among humans and non-humans must be considered seriously in order to develop and realize the enabling conditions of post-labor in the contemporary context.

\section{Stiegler's Reinvention of Work beyond Employment}

Simondon predicts that the problem of emotional conflicts and alienation stemming from the opposition between the pre-industrial mode and the industrial mode will be overcome through the realization of the post-industrial mode transductively unifying the two. Also, that it will be possible to realize this postindustrial mode by amplifying emotional and social connections and expanding transindividual relationship networks based on the spread of technical mentality and on IT networking. However, Stiegler points out that hyper-industrialization rather than post-industrialization arrived with information networks. If the modern industrial era was characterized by "calculation" (Heidegger) and "bourgeois capitalism" (Marx), then the hyper-industrialization era signifies an age where such characteristics of the modern industrial society, accelerated along with the rise of bio-digital technology, have been expanded and strengthened across daily life and the cultural and symbolic worlds beyond production and industry, an age that therefore has come to produce an IT-based "control society" (Deleuze).

Stiegler's diagnosis, which may seem somewhat pessimistic, proceeds with discussions on a basis that is different from Simondon's understanding of technology. First, unlike Simondon, Stiegler postulates the joint emergence of technology and humans by stressing that the latter did not exist before the former. ${ }^{11}$ The argument that humans and technology were constructed at the same time from their origins is made in order to criticize, as does Simondon, the dominant view that technology destroys the fundamental relationship between humans and the world. However, the differences between Simondon and Stiegler in their views on the relationship between technology and humans are clear. In Simondon's view, the generation of technology is not contemporaneous with humans. Technology is one of the many ways in which humans form a relationship with the world. Before the generation of technology, humans lived in a non-technical, magical world. In other words, technicity emerged together

11 "The technical inventing the human, the human inventing the technical. Technics as inventive as well as invented" (Stiegler, 1998, p. 137). 
with religion as this primitive, magical relationship between humans and the world underwent a phase-shift (déphasage). To Simondon, a mode of magical relationships where humans and the world were in accord with each other without a distinction between the subject and the object is more fundamental than technology and religion are. ${ }^{12}$ Consequently, if Simondon approaches the relationship between technology and humans from the perspective of generative ontology (individuation) transcending an anthropological perspective, Stiegler can be said to still maintain both a conceptual image of Homo faber and an anthropological perspective on technology. Stiegler basically views humans as beings deficient in particular essence, such as the strength of lions or the swiftness of zebras, and defines technology as a "prosthesis" $(2009$, p. 8) that supplements such human deficiencies. If Simondon's ontogenetic thought opens up a possibility of de-anthropocentric humanism between machines and humans, Stiegler's thought does not free itself from anthropocentric humanism.

Furthermore, Simondon's mechanological technology focuses on the technical essence of operational functioning, Stiegler's technics focuses on mnemotechnics, which was created for the preservation of information and memories and includes writing, records, books, photographs, cinema, television, and Internet. Simondon notes the capacity of technology to realize preindividual potentials as transindividual while Stiegler is interested in the effects of technology, which historically has organized and structured human life in diverse ways. Constituting artificial memory that makes possibilities that are not determined by biological programs realizable, mnemotechnical devices consist of primary retentions and secondary retentions that construct the internal consciousness of time in a Husserlian sense, to which tertiary retentions have been added through technical objects. "I's" conscious life consists of the organization of primary retentions selected by secondary retentions, and the relationship between primary retentions (R1) and secondary retentions (R2), too, is determined by tertiary retentions (R3): "R3(R2(R1))" (Stiegler, 2014, p. 52). Stiegler understands humans' individual lives and collective culture as consisting of these tertiary retentions (prostheses essential to the human species). Mnemotechnical devices discretize and grammatize human experiences, which are especially fluid and continuous. "Grammatization is the production and

12 Consequently, in Simondon's case, the entire relationship between humans and the world can be integratively reconstructed only when the relationship between technology and religion complementarily strikes a balance. Efforts to recover the magical relationship by connecting the technical and the religious constitute an aesthetic task, and from this task derives the possibility to overcome fundamental alienation due to discontinuity with the world. This is why Simondon's post-industrial technical objects can overlap with aesthetic objects. See the preceding Note 10. 
discretization of structures (which traverse pre-individual milieux and transindividual organization, and which are supported by technical or mnemotechnical apparatuses)" (Stiegler, 2014, p. 55). Just as the emergence of the alphabet contributed to the unification and control of the Western spirit as a techno-logical condition of all knowledge, mnemotechnical devices, which program images, voices, bodies, and gestures in the forms of data and information, grammatize conscious life today.

Finally, what is noteworthy in relation to this is Stiegler's concept of transindividuation. He critically inherits Simondon's concept of psychologicalcollective individuation mediated by technology by modifying it into psychiccollective-technical individuation. According to Stiegler, humans' individuation is characterized by the simultaneous formation of psychic individuation (I), collective individuation (we), and technical individuation (the environment connecting me and us, the environment mediated by mnemotechnics). The psychic individual called "I" cannot be conceived of without belonging to the collective individual called "we." This is because "I" is constructed through the process of "adopting" (i. e., accepting a past not belonging to one's direct ancestor as one's own) the group's historical legacy. "I" is in a metastable process, a process of psychic individuation, instead of a substantial state, and "we" likewise is a process of collective individuation. The individuation of "I" is recorded there, and the individuation of "we" is generated through conflicting individuation among "I's." As stated above, Simondon sees the simultaneous generation of "I" and "we" as psychic-collective individuation and defines this as belonging to the transindividual beyond the biologically individuated level. However, Stiegler adds to this the "individuation of a technical system (something Simondon strangely didn't see)" (2014, p. 51; emphasis original). In Stiegler's view, Simondon addresses the concretization of technical objects but does not direct his attention to technical systems, which already exist as a commonality even though, like the preindividual, they cannot be experienced as they are by psychic individuals or groups. Stiegler claims that none other than these technical systems are indispensable as an epiphylogenetic condition (condition épiphylogénétique) activating the transductive relationship between the individual and the transindividual. Embracing André Leroi-Gourhan's anthropological thought, he argues that humans' biological evolution has proceeded alongside technical evolution (the material exteriorization of memory) and that humans in particular have been able to transcend the limitations of adaptation due to natural selection thanks to the invention of epiphylogenetic memory. According to him, the post-Zinjanthropian human race has developed three types of memory: (1) genetic or specific memory (mémoire génétique ou spécifique); 
(2) epigenetic or nervous memory (mémoire épigénétique ou nerveuse); and (3) epiphylogenetic or techno-logical memory (mémoire épiphylogénétique ou techno-logique). While specific memory is free from experience and physical memory disappears along with that body, technical memory is accumulated and transmitted as a legacy (Stiegler, 1998a, pp. 250-251). Consequently, he newly defines psychic-collective-technical individuation, where the psychic, collective, and technical interact and syncrystallize, as transindividuation. "Individuation is not double but triple; psychic, collective and technical, each one unthinkable without the others - they are in a three-pronged transductive relationship" (Stiegler, 2014, p. 70). Simondon understands the preindividual as Nature's potentiality, or as metaphysical Being's generative capacity and sees technology as an expressive medium of such ontological potentials. Stiegler emphasizes the simultaneous relationships of interdetermination among the three levels of the psychic, collective, and technical, once again establishing networked technical systems themselves as constituting a preindividual environment of human life. In my view, however, if Simondon's transindividual is examined in its trilateral relationship with the preindividual and the technical from the perspective of the non-anthropocentric philosophy of becoming, then Stiegler's transindividuation in fact does not transcend the framework of philosophical anthropology, which focuses on the historical interaction in the bilateral relationship between the technical environment and the human race, notwithstanding its triple emphasis.

Based on such fundamental differences in the understanding of technology (i. e., whether one adopts a non-human perspective or a human perspective), Stiegler cites the destruction of the possibility of Simondon's transindividual collectivization as the greatest problem of the age of hyper-industrialization since the 1990s. This was something Simondon was unable to experience. According to Stiegler, the mnemotechnical devices of the 3rd Industrial Revolution, or the grammatization of IT engineering proceed beyond the sphere of language all the way into the conscious and the unconscious, into gestures and actions, and organize the conditions of individuation as selective devices interpreting the legacy of a preindividual past. The mnemotechnics of hyper-industrial society, where modes of cultural production and consumption that make use of digital networks are combined with the categorical imperative of the capitalist economy, prompt human individuals' unique desires to regress into impulses toward identical objects of consumption, weaken individuals' capacity for transindividuation, and bring about the "liquidation of social relations" (Stiegler, 2010, p. 57). Individuals who have lost singularity, or Deleuzian dividuals, ${ }^{13}$

13 "We're no longer dealing with a duality of mass and individual. Individuals become dividuals, and masses become samples, data, markets, or banks" (Deleuze, 1995, p. 180). 
whose attention has been seized by hyper-industrial mnemotechnical devices and who are infinitely divided in order to serve the interests of the market, are only any "ones," no longer "we" of true solidarity. This refers to beings whose conscious attention does not operate so as to make possible thought on the lives of both individuals and groups in terms of long-term predictions but has been seized by the short-term consumption of disposable goods; beings who operate only as single functional elements within the technical systems of networks; beings who search databases (DBs) and immediately become parts of those DBs and exhaust themselves where they consume - any "ones" consisting of such beings produce "becoming-arthropod of society" (Stiegler, 2014, p. 74) instead of the transindividual collectivization of human society. Preindividual environments are transformed in terms of both technological engineering and the industries, and diverse prostheses surrounding the living human body control symbolic, mental, and motor functions. Humans come to resemble arthropods halfway between ants (covered with prostheses such as wearable devices) and spiders (eating themselves in networks), and human society becomes a mere multi-agent system resembling an insect society instead of collectivizing transindividually. Stiegler criticizes this type of information society, which Simondon optimistically predicts will achieve internal resonance capable of overcoming severance and isolation through the communication and sharing of information. In the contemporary context, that type of information society has become an organized society so controlled through the construction of a digital network environment that individuation is no longer possible and so synchronic that the accumulation of individual experiences has also become an impossibility.

Stiegler links such loss or impossibility of psychic-collective individuation to proletarianization in the hyper-industrialization era.

The proletarian, we read in Gilbert Simondon, is a disindividuated worker, a laborer whose knowledge has passed into the machine in such a way that it is no longer the worker who is individuated through bearing tools and putting them into practice. Rather, the laborer serves the machine-tool, and it is the latter that has become the technical individual (Stiegler, 2010, p. 37).

When seen from Simondon's perspective, these de-individuated laborers are humans who no longer play the role of technical individuals, humans who therefore no longer form relationships with technical objects physiopsychologically through physical motion. Unlike Stiegler, Simondon understands this de-individuality of laborers as an occasion for readjusting the relationship between humans and machines, or as a positive condition for transindividual 
collectivization transcending labor communities. According to him, humans should not insist on labor that can be performed by technical individuals but, instead, should now focus their efforts on constructing a social system where they can communicate equally, through the mediation of technical individuals in technical activities that have been enhanced to be above labor, and participate in technical operation together. However, Stiegler understands this de-individuality of laborers in terms not of its physio-psychological aspect but of its intellectual aspect, or in the sense of the dehumanization and mechanization of knowledge, and evaluates it negatively. In other words, the hyper-industrial expansion of both full-fledged mechanization-automation and the grammatization of mnemotechnics have deprived laborers of savoir-faire and savoir-vivre, even savoirs théoriques, thus producing de-individuated laborers, or proletarianization.

The hyper-industrial societies that have grown out of the ruins of the industrial democracies constitute the third stage of completed proletarianization: in the nineteenth century we saw the loss of savoir-faire, and the loss of savoir-vivre in the twentieth, and in the twenty-first century we are witnessing the dawn of the age of the loss of savoirs théoriques, of theoretical knowledge - as if the cause of our being stunned was an absolutely unthinkable development (Stiegler, 2015, p. 10).

According to Stiegler's diagnosis, the absolute majority is in a state of "systemic stupidity" in hyper-industrial society due to such deprivation of knowledge. Only an extremely small minority can read, write, think, and engage in activities of creative invention, and, in particular, total automation, which has been made possible by the rise of the "four horsemen of the Apocalypse (Google, Apple, Facebook and Amazon)" and digital technology, contributes to the completion of the "generalized stupefaction" of hyper-industrial society (Stiegler, 2015, p. 9).

If so, then where does Stiegler find the possibility of escape from the crisis of human life caused by digital mnemotechnics in automated society in an age of hyper-industrialization, or from total proletarianization? His solution is to practice "techno-pharmacology," which can also be referred to as "psychopolitics," "noopolitics," or "neguanthropology" (néguanthropologie). In a word, because all technologies as tertiary retentions are essentially pharmakons, the solution is to convert the toxicity of these pharmakons into the efficacy of medicine and to create a "new hyper-industrial age constituting an automatic society founded on de-proletarianization" (Stiegler, 2015, p. 13). If proletarianization is based on automation, de-proletarianization is based on de-automation (désautomatisation). However, this de-automation is not a return to the state before automation but is the active reuse of automation. Stiegler argues that, in a full-fledged crisis of life and knowledge due to automation, post-labor "work" (travail) 
transcending “employment" (emploi) must be developed. According to L'Emploi est mort, vive le travail! (2015a), if employment is proletarianization under subordination to automated systems, work signifies the manifestation of the capacity for de-automation, whereby one leaves employment and, based on technical automaticity, freely creates and invents. Stiegler stresses that, in the hyper-automation age, it must become possible, based on highly developed technical automaticity, to realize a life where one is no longer employed but engages in one's unique work, or, in other words, a way of life where one shares savoir-utiliser regarding technical tools, joy of achievement, and knowledge and savoir-vivre, thus being based on savoir-être-ensemble.

Stiegler's argument that work transcending employment should be realized, is essentially also tracing transductive relationships among the three levels of transindividuation and searching for a possibility for "I" and "we" to cut across, to communicate with, and to change one another and to individuate potentials in new ways instead of existing as groups of mutually indifferent and fragmented dividuals. In other words, we must critically intervene in the ways in which the mediation of digital mnemotechnics overdetermines the conditions of individuation and reorganizes the relationships among "I" and "we" and must endeavor to convert the toxicity of technology into the efficacy of medicine. For example, cases of toxicity including excessive obsession with digital technology, weakened attention such as attention-deficit hyperactivity disorder (ADHD), and forestalling of the maturation of thought and the development of socialization abilities among younger generations have manifested through the transformation of desire into impulses, which is the result of the infiltration of economic marketing into networks. Stiegler argues that, in order to resist a libidinal economy based on such impulses and for consumer capitalism to be free from an accelerated system of indifference that does not take care of life, above all, we must actively pursue taking care of our intellect, which is the ability to think, and recovering the capacity for knowledge. In other words, instead of degenerating into machines hired by automated technical systems, we must foster the ability for de-automation, which is the ability to invent and create the new based on the automaticity of technology. That is, we must foster our ability for savoir-penser, instead of desire transformed into impulses, savoircréer-la-valeur-pratique instead of use value or exchange value. In L'Emploi est mort, vive le travail! (2015a), Stiegler presents freeware as a possible model of work in which individuals and groups creatively engage in transindividual relationships in opposition to the employment paradigm, which gives rise to indifference and impoverishment. Freeware refers to software of which the use, study, modification, reproduction, and distribution are technically and legally 
permitted to all users. In the field of freeware, developers endlessly improve other developers' work so that software open to all people is continuously improved by everyone's contribution. Moreover, in order to activate work methods such as this freeware, Stiegler proposes a "contributive economy" (économie contributive), where members live by sharing all types of knowledge and enjoying the benefits together, instead of an "economy of indifference," which accelerates competition and consumption. To phrase it differently, what is necessary is not an economy where people subsist by means of employment and wage labor but one where they can live and work based on "contributive income" (revenu contributif). Contributive income refers to income that is paid to everyone so that all people can develop forms of knowledge with social value while realizing their respective potentials. Stiegler sees the creation of modes of life for human existence beyond the level of impulses and desire for biological survival through critical intervention in technical conditions and politico-economic conditions as an urgent contemporary necessity to be able to convert technology into the arts, toxins into medicine, and employment into work.

\section{Conclusion}

According to the shared insights of Simondon and Stiegler, technology and transindividuality are the most essential components required to enable a post-labor model that can overcome the crises of labor and employment in an era of technical automation. Post-labor should not be seen as merely a system of rest or recreation, but as the creation of a transindividual way of life that creatively realizes the preindividual potentials based on technical achievements.

Simondon affirms the transductive generative potentiality of preindividual reality inherent in humans and predicts that it will become possible for transindividual technical culture of emotional solidarity to realize such a feature through the medium of IT networks. Noting proletarianization due to the hyper-industrialization of accelerated consumer capitalism, which is contrary to such anticipation on Simondon's part, Stiegler stresses the critical literacy of pharmakonic influence of technical media that organize transindividual relationships. While critically inheriting Simondon's thought on technology and transindividuality, Stiegler seems to remedy points at which Simondon's vision encounters difficulties in a contemporary technical situation. However, Stiegler's work might reduce Simondon's insights in that it is not free from an intellectualistic tendency to emphasize knowledge rather than affectivityemotionality and it is not free from the anthropocentric humanism of the instrumental use of technology. The gist of Stiegler's culture of work transcending 
employment is that, through the use of the capacity of technology not as a toxin but as medicine, wisdom of life that realizes each individual's potential in socially valuable ways should be practiced. This signifies an urgent proposal seeking to save human life from the control system of technocapitalism. In contrast, Simondon's technical culture beyond labor is based on transindividual collective relationships that are formed through the communication of preindividual potentials with technical objects. This implies a posthumanistic vision in that it assumes the capacity of technology to mediate between the preindividual and the transindividual beyond technical instrumentalism, which is anthropocentric, and opens up transductive relationships among humans and non-humans (nature and technology) on an affective-emotional level.

In my view, Stiegler's urgent proposal fundamentally must be concretized within the Simondonian vision. However, for Simondon's unfinished project to be realized today, Stiegler's critical literacy, which seeks to convert the toxicity of technical media into the efficacy of medicine, is inevitably required. In order to transcend both labor communities of fragmented dividuals as well as control society and to realize transindividual technical culture, it is imperative to recover technology's capacity for bearing preindividual potentials through critical intervention in the techno-capital system. A post-labor way of life where humans and non-humans can work together will become a possibility when Simondon's faith in the preindividual potentials inherent in humans is fused with Stiegler's critical literacy of hyper-industrialization into our knowledge and usage of technology.

\section{Reference}

DELEUZE, G. "Postscript on the Societies of Control". In: Negotiations 1972-1990. translated by Martin Joughin. New York: Columbia Univ. Press, 1995. pp. 177-182. KIM, Jae-Hee. "Transindividual-transversal Subjectivity for the Posthuman Society". Kriterion, Belo Horizonte, Nr. 137, pp. 391-411, Ago. 2017.

SIMONDON, G. (1958). "Du Mode d'existence des objets techniques". Paris: Aubier. On the Mode of Existence of Technical Objects, translated by Cecile Malaspina and John Rogove, Minneapolis: Univocal, 2017.

SIMONDON, G. "L'Individuation à la lumière des notions de forme et d'information". Grenoble: Millon, 2005.

SIMONDON, G. "La mentalité technique". In: Sur la technique, PUF. 2014. pp. 295-313. “Technical Mentality". In: Parrhesia 07. translated by Arne De Boever, 2009. pp. 17-27. STIEGLER, B. "Technics and Time 1: The Fault of Epimetheus". Translated by R. Beardsworth and G. Collins. Standford, CA: Standford University Press, 1998. 
STIEGLER, B. "Technics and Time 2: Disorientation". Translated by Stephen Barker. California: Stanford University Press, 2009.

STIEGLER, B. "For a New Critique of Political Economy". Translated by Daniel Ross. Cambridge, UK: Polity Press, 2010.

STIEGLER, B. "Symbolic Misery". Cambridge, UK: Polity Press, 2014.

STIEGLER, B. "L'emploi est mort, vive le travail!". Fayard, 2015a.

STIEGLER, B. "Temps et individuations technique, psychique et collective dans l'œuvre de Simondon". Intellectica, 1/2, Nr. 26-27, pp. 241-256, 1998a.

STIEGLER, B. “Automatic Society”. Episteme (14), pp. 3-28, 2015. 